\title{
A Single Factor Strategy Based on the Announcements of Shareholders Increasing Stakes in Chinese Financial Market
}

\author{
Jiayi Wang ${ }^{1, *}$, Yibing Chen ${ }^{2}$

\begin{abstract}
${ }^{1}$ The Cambridge School of Weston Weston Massachusetts United States 02493
${ }^{2}$ Woldingham School Caterham England United Kingdom CR3 7YA

Corresponding author Email: jackiew7090@gmailcom
\end{abstract}

\begin{abstract}
In this study, we use the public announcements of shareholders increasing stakes to examine the impact of the events to stock prices. We prove that shareholders increasing stakes have a positive impact on stock prices as the number of stocks with a higher daily return after the release of the announcements is larger than the number of stocks with a decrease in return. Among companies, managers, and individuals in companies, the announcements associated with managers increasing their stakes yield the highest number of stocks with an increasing return and provide the best performing strategy comparing the other two. We, then, design an investment strategy based on the announcements of managers increasing stakes, and justify the effectiveness and efficiency of it by showing the excess return in comparison to the market return.
\end{abstract}

Keywords: Stock, strategy, shareholder, announcement.

\section{INTRODUCTION}

In Chinese stock market, shareholders changing their stakes is not a rare event. A growing trend in the number of cases is presented in recent data. Since 2007, the information of stake changes is required to be open to public; thereafter, stock investors and scholars have started to investigate and analyze the deep-seated motives and potential impacts from the event. The arguments are both-sided. Scholars viewing shareholders increase their stake as a positive sign assert that the increasing in stakes is a representation of shareholders' growing confidence for the prospects of the company, while those who disagree claims that there is no effect at all. An article from Securities Times China analyzes this event from two aspects. According to the essay, the increase of major shareholders' stakes illustrates their optimistic attitude towards the future development of the company. Once the company has a promising prospect and widely publicize it, the company's stock price will be guaranteed to rise. On the other hand, the article views the issue in terms of the law of supply and demand. Shareholders increasing their stake causes demand to exceed supply and consequently leads to the decline of the liquidity in the market. A sense of hunger and thirst will be formed in the investors as a result, driving the stock prices up [1]. However, on the contrary to the optimistic point of view regarding shareholders increasing stakes, multiple researches done by different scholars illustrates a very limited impact from shareholders increasing stakes to the stock market. In Xingjuan Huang, Zichun Yan, and Hui Wang's 2014 article, they state that no significant impact is there for individual investors based on their analysis of shareholders increasing stakes from a sample of 245 companies [5]. Other studies conclude similar results, such a study published by Longbing $\mathrm{Xu}$ and Bin Wang in 2021, claiming the absence of a long-term effect [3].

With the improvement of the trading mechanism in and the growing number of major shareholders changing their stakes in the secondary market, further investigation in the topic is essential and meaningful. This paper examines the impact from shareholders increasing stakes to stock prices in Chinese financial market, proving what Wenhe Fu concludes in his 2020 paper that a positive influence on the trend of the company's stock price is exerted by the behavior of shareholders increasing stakes. The paper discusses a single factor strategy based on the announcements of shareholders increasing stakes and proves the effectiveness and efficiency of the strategy. 
The paper is organized as follow. Section 2 presents three hypotheses and the reasons behind them. Section 3 is the methodology, including information about data sets and calculations. Section 4 reports the result from testing the hypothesis based on the methodology. The results of back testing is presented in Section 5 and Section 6 is the conclusion.

\section{HYPOTHESES}

\section{H1: The efficient market hypothesis is invalid.}

The efficient market hypothesis states that any new information released to the market is immediately reflected on the stock prices, and thus, no further analysis can generate excess return. To design a profitable investment strategy, the first step in the study is to justify the invalidity of the efficient market hypothesis, proving the existence of an impact on stock prices from the release of the announcements.

$\mathrm{H} 2$ : The announcements of shareholders increasing their stake have positive impacts on the stock prices.

Shareholders' behavior of increasing their stakes can be an incentive strategy to allure individual investors in some occasions when government or companies intentionally encourage the increase of stakes to stabilize the market or the stock price. Yet, we try to prove shareholders increasing their stake as an affirmation of their confidence in the performance of the company. The rise of confidence represents a promising prospect for the company's development, delivering a positive sign to investors and leading in an increase in stock return consequently.

H3: The announcements associated with different types of shareholders increasing their stakes have different impacts on stock prices.

Shareholders are separated into three types for further analysis: companies, managers in companies, and individuals in companies besides managers. Because of the different position that these people hold and the assuming potential insider information they can obtain, we make the assumption that these elements influence the perception that individual stock traders receive, and therefore, leaves a different degree of impact on stock prices. We try to support the hypothesis by further analysis based on the changes of stock return after the release of the announcements in comparison with the stock return prior to the announcements.

\section{METHODOLOGY}

\subsection{Data}

All data are collected from TuShare, a python opensource package with fundamental data about the Chinese financial market. Two major data sets are extracted from it: 1) stock daily return data; 2) data about announcements on shareholders changing stake. To facilitate further analysis, the first data about daily return is converted into the logarithmic return from the original arithmetic rate of return, as the logarithmic rate of return enables direct addition when calculating stock returns over a wider time span. The market return is calculated based on the CSI (China Securities Index) 500. The latter data set includes all information associated with announcements of shareholders changing stakes, including announcement release date, trading types, shareholder types, stock codes, changing ratio, and etc. The major and most relevant variables to our later analysis are trading types (increasing stake or decreasing stake), holder types (company, manager, or individual inside company), stock codes, and announcement release dates. Announcements associated with decreasing stake are deleted from the data set. Our study focuses on shareholders increasing their stake.

In 2007, a regulation about shareholders changing stakes was announced by China Securities Regulatory Commission (CSRC), formally known as Regulations Regarding Shareholding and Changing by Directors, Supervisors, And Senior Managers of Listed Companies [2]. The regulation specifies the time span that listed companies are required to report the behavior of changing stakes by their shareholders being within two trading days after the change taking place. According to the regulation, the report must include basic information, such as the changing volume, changing ratio, changing the date, and etc. The announcement of the regulation, alongside with later updates announced in 2012 and 2018, ensures the openness and transparency of shareholders changing their holdings. Insider news is transformed into public information, causing changes in shareholders' stakes to be more relevant and influential to stock prices. Because of the regulation, information about shareholders changing their stake is easily acquirable. We extracted the information of released announcements starting from the announcing year of the regulation, 2007, to the end of February 2021. 14 years of information about the released announcements is sufficient for our analysis prior to strategy design as well as the back-testing of the efficiency of the strategy.

\subsection{Calculations}

\subsubsection{Part I: Testing Hypothesis}

To test the three hypotheses, we need to show the significance of stock price fluctuations after the release of the announcements. We use the daily returns of each individual stock to test the fluctuations associated with the announcements. Daily returns, the changes in the price of a stock, are an accurate measure of the performance of each individual stock and have a direct association with the effectiveness and efficiency of our 
strategy. An increase in daily return after the announcement is a representation of a positive impact to stock prices from the released announcement, while a decrease shows a negative influence. The effect of the announcements is measured by a simple difference between the stock return before and after the announcement: where $\mathrm{Ri}, \mathrm{t}+\mathrm{n}$ is the sum of $\mathrm{n}$ days of stock i's daily return after the release of the announcement on day $\mathrm{t}$, and $\mathrm{Ri}, \mathrm{t} \_\mathrm{n}$ is the sum of daily return of stock $\mathrm{i} n$ days before the release of the announcement on day t. A positive $\mathrm{d}$, in this case, shows that the stock return of stock $i$ after the release of the announcement is greater than the return before the announcement, demonstrating an increase in the stock return and a positive effect cast on the stock price by the release of the announcement. Similarly, a d less than zero means a larger daily return of stock $i$ before the announcement than the stock return after it, and hence, represents a decrease in the stock return after the announcement and a negative effect on the stock price.

\subsubsection{Part II: Testing Strategy}

We measure the efficiency of our strategy through daily logarithmic rate of return, mainly calculated by basic matrix operation. All data sets extracted from
TuShare are automatically formatting as arrays, making matrix operations simple and convenient. To calculate the final daily return of the strategy, we utilize two matrices:

where Rstrategy is the Matrix of the return from our strategy, $\mathrm{S}$ is the signal Matrix $\mathrm{S}$, and $\mathrm{R}$ is the daily return Matrix R. From Equation 2, we get a new Matrix Rstrategy with the same dimension as Matrix $\mathrm{S}$ and Matrix R. The final step to calculate the return from our stock by adding up all row elements in Matrix

\section{DATA ANALYSIS}

\subsection{Hypothesis 1}

The efficient market hypothesis is invalid.

To prove the invalidity of the efficient market hypothesis, we need to show the significance of stock price fluctuation after the release of the announcements. Based on Equation 1, we use $\mathrm{n}$ from 1 to 20 and implement the equation to all released announcements associated with shareholders increase their stake, testing for any significant changes of stock return after the announcement.

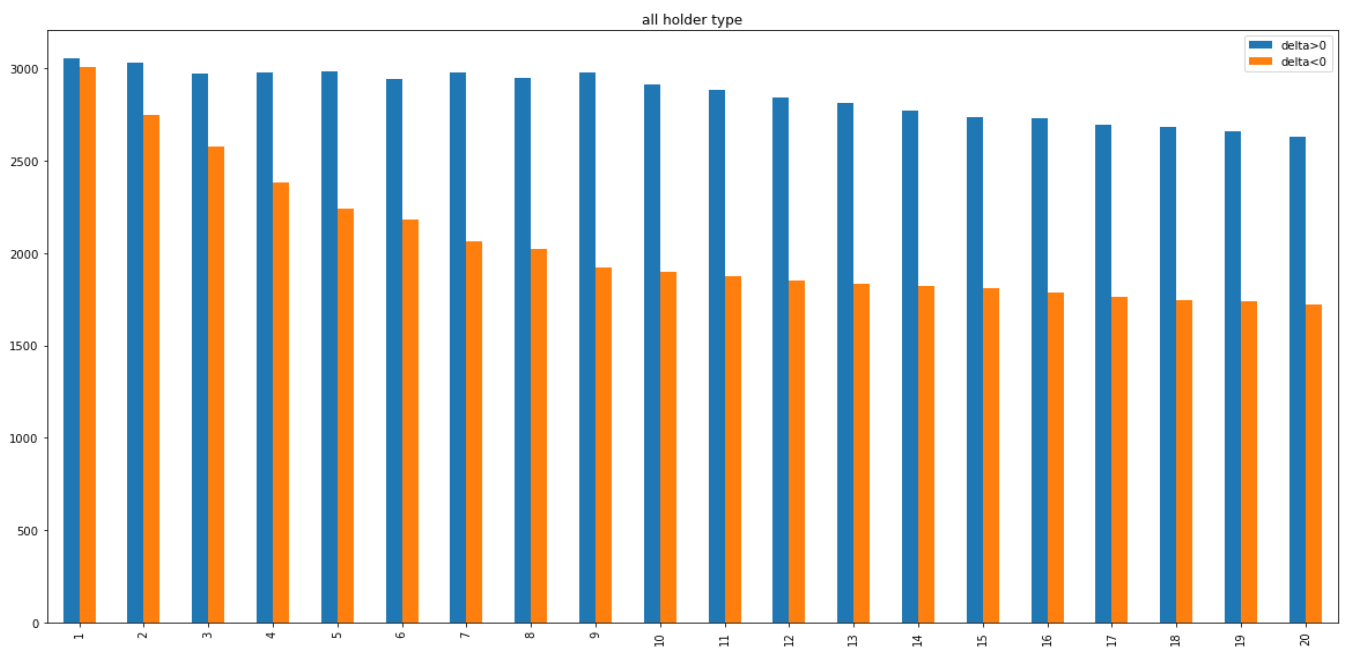

Figure 1: 5 of all shareholder type

Rstrategy. The resulting values are the daily return generated by the strategy.

$$
\begin{aligned}
& \mathrm{R}=\left[\begin{array}{ccc}
a_{11} & \cdots & a_{1 n} \\
\vdots & \ddots & \vdots \\
a_{n 1} & \cdots & a_{n n}
\end{array}\right] \\
& \mathrm{S}=\left[\begin{array}{ccc}
a_{11} & \cdots & a_{1 n} \\
\vdots & \ddots & \vdots \\
a_{n 1} & \cdots & a_{n n}
\end{array}\right]
\end{aligned}
$$

Where Matrix $\mathrm{R}$ is the daily return matrix of all stock in Chinese financial market and Matrix $\mathrm{S}$ is the signal matrix. For both matrices, the columns are trading dates, while the rows are stock codes. We form the signal Matrix $\mathrm{S}$ by setting the announcement release date and $\mathrm{n}$ days following it as 1 , while filling up the rest with 0 . In Matrix S, all elements are either 1 or 0 depending on the $\mathrm{n}$ value that we choose. Then we measure the return from the strategy by taking the Hadamard product of the two matrices:

Note: The vertical axis in the graph is the number of 5 corresponding to the various values of $n$ on the horizontal axis. The blue bars are the number of positive 5 with different $n$, while the orange bars are negative 5 . 
In Figure 1, both the blue bars and the orange bars represent changes in the stock daily return, despite one being positive, the other negative. The high number of the changes after the release of the announcement are sufficient to refute the efficient market hypothesis and hence, support our first hypothesis.

\subsection{Hypothesis 2}

The announcements of shareholders increasing their stake have positive impacts on the stock prices.

As shown in Figure 1, when $\mathrm{n}$ is ranging from 1 to
20 , the number of positive 6 exceeds the number of negative 6 regardless of the values of $n$. Representing an increase in daily return after the release of the announcement, the positive 6 in Figure 1 is a direct proof of Hypothesis 2, illustrating the high possibility of an increase in daily returns taking place after the announcement in comparison to a decrease.

\subsection{Hypothesis 3}

The announcements associated with different types of shareholders increasing their stake have different impacts on stock prices.

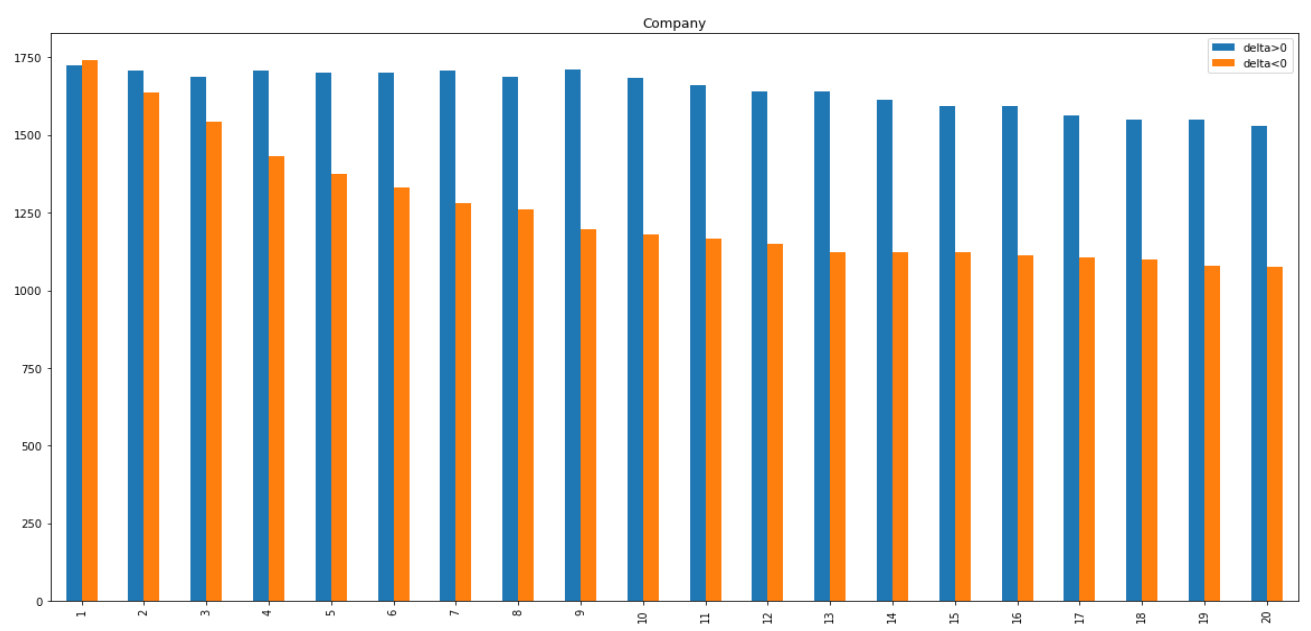

Figure 2: $\delta$ of companies as the shareholder type

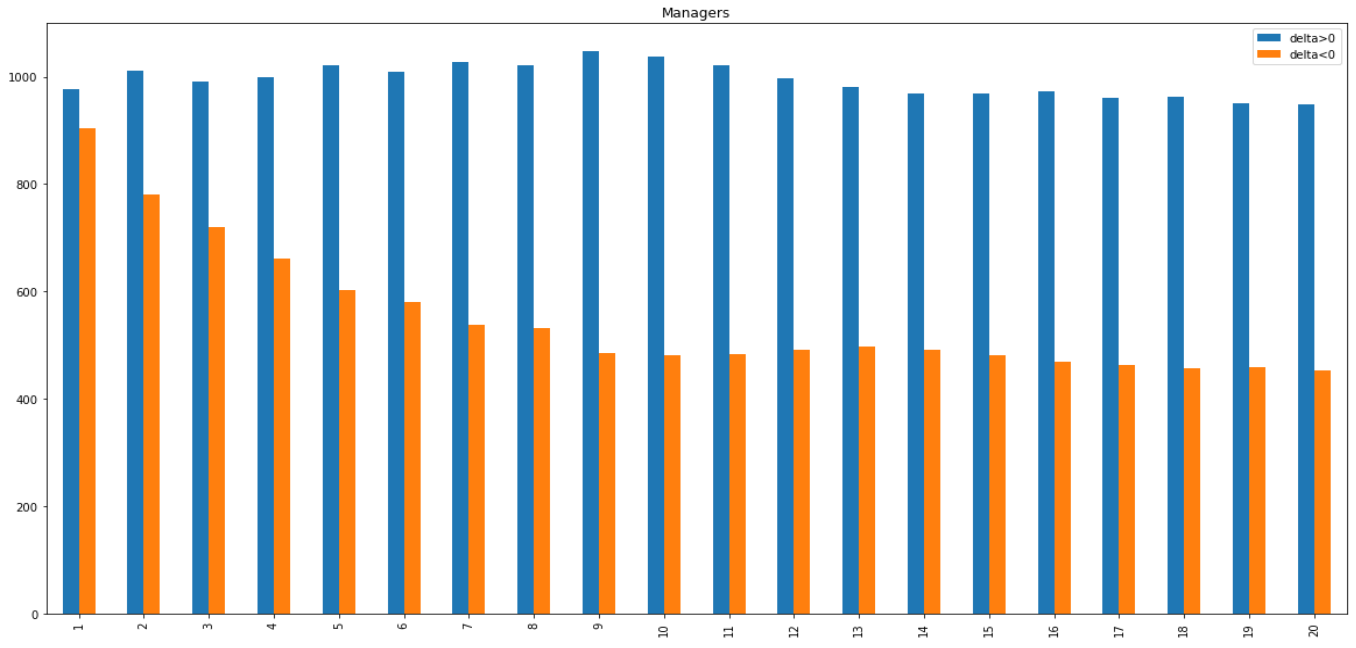

Figure 3: $\delta$ of managers as the shareholder type 


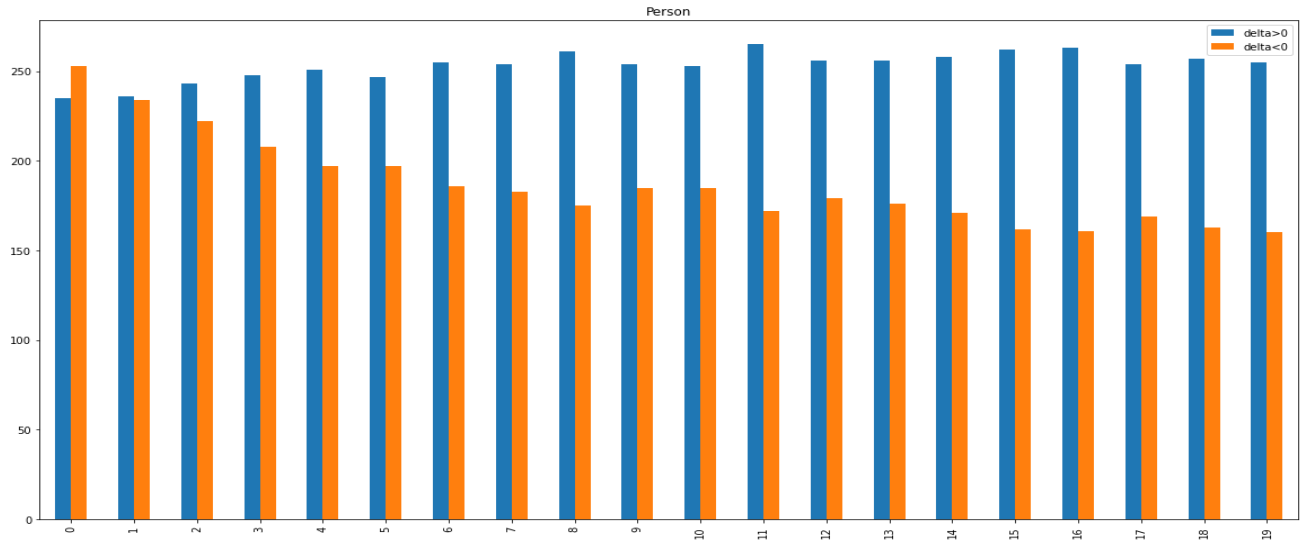

Figure 4: $\delta$ of individuals in a company other than managers as the shareholder type

To justify the third hypothesis, we implement Equation 1 separately to all three types of shareholders presented in the data set: 1) companies; 2) managers; 3) individuals in companies other than managers. We, again, look for the number of positive and negative 6 to examine whether these three kinds of shareholders cast different effects on the stork return.

Among Figure 2, Figure 3, and Figure 4, the distinctions between these three shareholder types are obvious. The differences between the number of positive 6 and negative 6 , show by the gaps between the heights of blue bars and the orange bars on the graph, are the greatest in Figure 3 regardless of the value of n, which means that managers increasing their stakes yields the highest possibility of an increasing stock return after the announcement comparing to both companies and other individuals increasing holdings. When we take $\mathrm{n}$ as 1 , the number of negative 6 exceeds the number of positive 6 in both Figure 2 and Figure 4. This high number of negative 6 illustrates that more stocks experience a decline of the daily return after one day that the announcement of companies and individuals increasing their stake is released. Hence, based on the abovementioned distinctions from the figures, we conclude that the announcements about different types of shareholders increasing their stake have dissimilar effects on stock price, and the announcements related to managers increasing their stake leads to the greatest number of increasing in daily returns. Figure 5 is a graphical illustration of the distribution that forms Figure 3 . With a skewness of 0.62 and a kurtosis of 1.35 , the figure further support our conclusion.

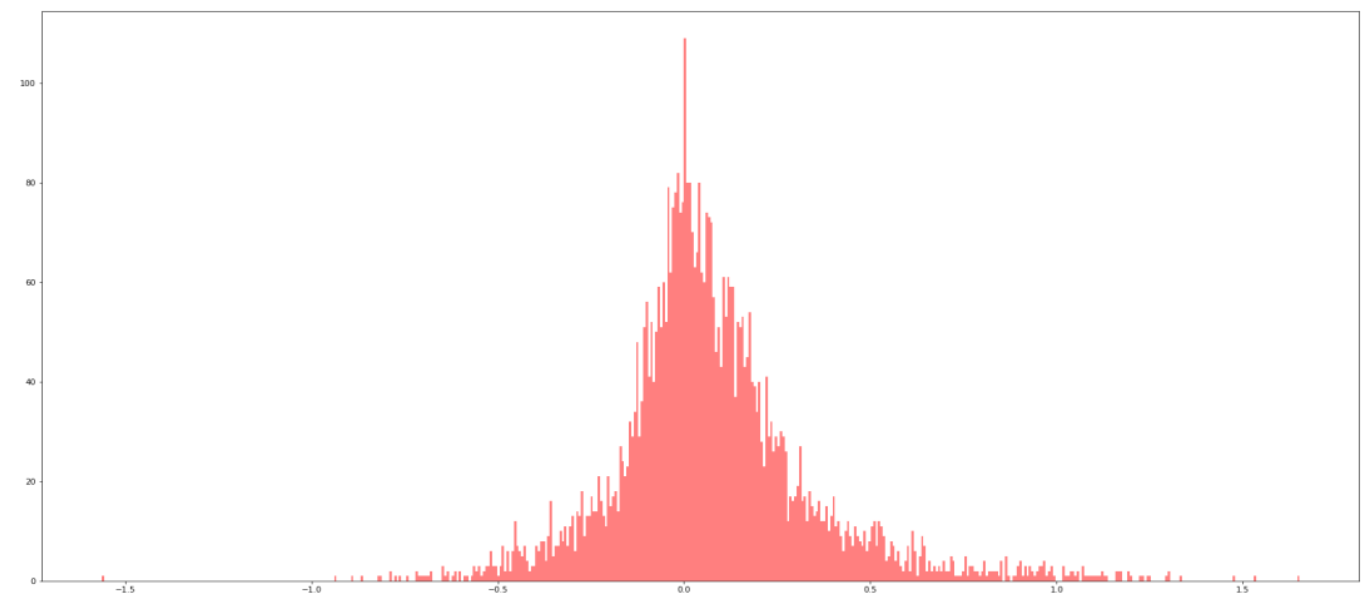

Figure 5: Histogram of the distribution in Table 1 
Table 1: Distribution of positive and negative 5 associated with the announcements of managers increasing stakes

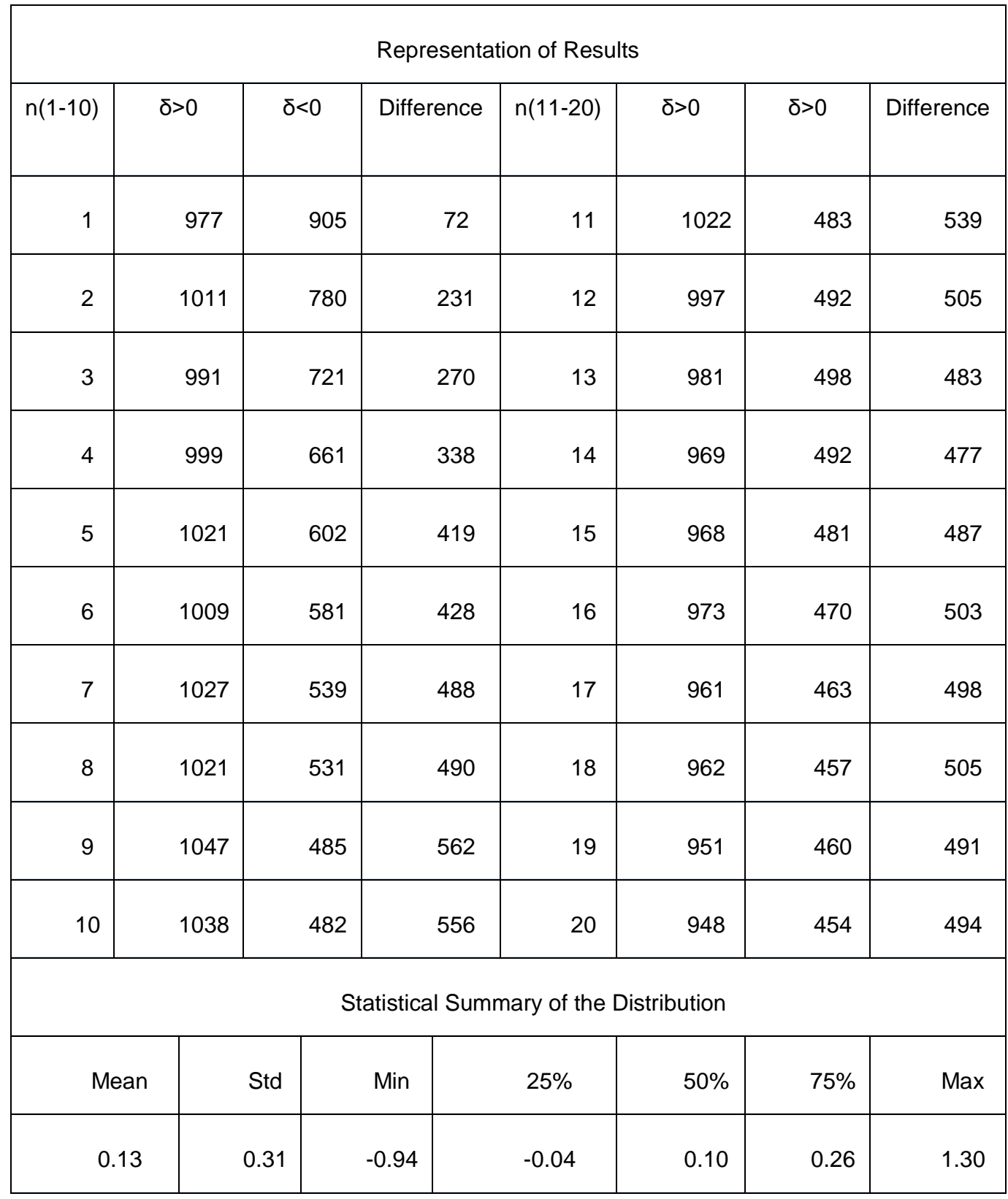

\section{BACK TESTING}

\subsection{Strategy Design}

\subsubsection{Procedures}

Four basic steps are implemented in the strategy, aiming for profit maximization:

1. On day 1, purchase all stocks that has an associated increasing stake announcement the next trading day after the release of the announcement.

2. Evenly distributed the capital among all stocks.

3. Hold the stocks for $\mathrm{n}$ days.
4. Make the next purchase at $n+1$ day after the preceding purchase.

All purchases are set on the following trading day after the release of the announcement to avoid the failure of buying the stock if the announcement is released on a non-trading day. The unification here eliminates the process of filtrating announcements that are not on a trading day and prevent the abandon of the stocks with potential high performance. No action, neither selling nor buying, is taken before the nth day until we sell all stocks that are currently holding on day $n$. The subsequent purchase is going to take place on the $n+1$ day, restarting the $\mathrm{n}$-day holding period of the stocks from step 1 . 


\subsubsection{Parameters}

Based on previous calculations and analyses, we set three parameters in the strategy to maximize the profit: 1) $n=15 ; 2$ ) shareholder type as manager; 3 ) change ratio of the increase $>0.1$. Based on Table 1, the largest difference between the number of positive and negative $\mathrm{S}$ is when $\mathrm{n}$ equals 9 , and the gap remains large until the value of $\mathrm{n}$ reaches 14 . Thus, we choose $\mathrm{n}$ as 15 to include the full period from day 4 to day 9 where the announcement is leaving significant positive effect on stock prices and cut off the days after day 15 where the positive impact from the announcement is shrinking. From testing Hypothesis 2, we prove that the announcements of managers increasing their stake have the best performance comparing to the other two shareholder types, companies and individual. To maximize the profit from our strategy as large as possible, we solely use announcements of managers increasing their stake as signals, abandoning all other announcements. The fundamental reason behind the last parameter of change ratio is to eliminating certain announcements to reduce the number of signals in the strategy.

Higher changing ratio often correlates with better performance; therefore, we use change ratio $>0.1$ as a parameter to simplify calculations as much as possible, while maximize the profit from the strategy in the meantime.

\subsection{Back testing}

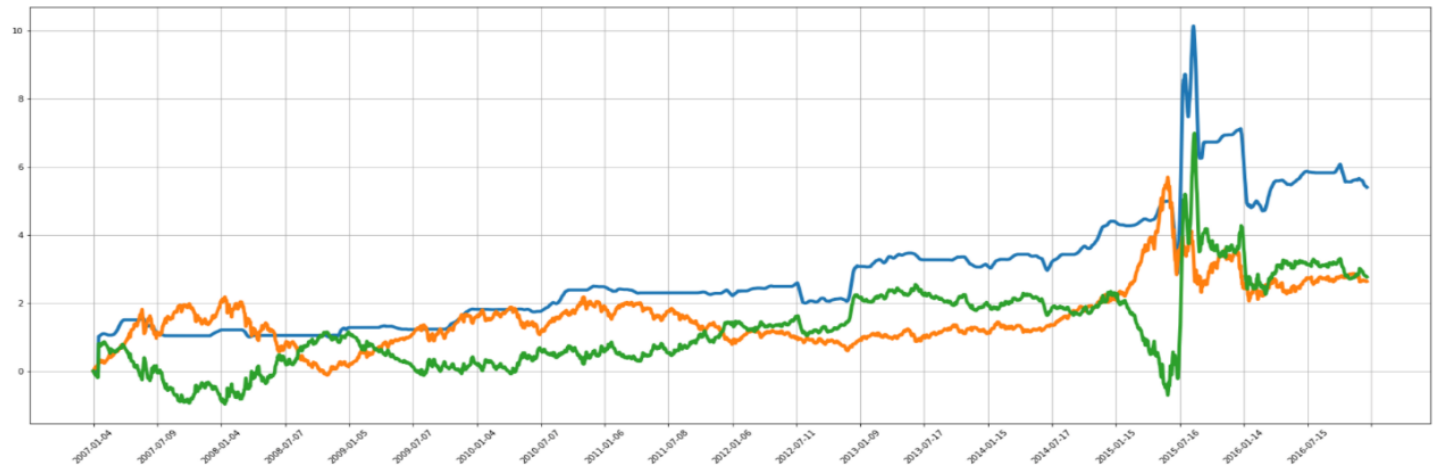

Figure 6: Back testing: comparison between market return and strategy return

Note: The blue line is the daily rate of return from the strategy; the orange line is the market return based on CSI 500; the green line is the positive abnormal return.

We choose the ten-year period from 2007 to 2016 to run the back testing, and Figure 6 is a graphical representation of the result. The figure is based on three data sets, most calculated in previous sections: the market return, the rate of return from the strategy, and the excess return. The blue line is representing the return from our strategy, the orange line is the market return, and the green line is the excess return. The excess return is calculated by subtracting the values on the orange line from values on the blue line, which is the market return from the return of the strategy. In the graph, all periods of time where the green line is above zero represents a positive abnormal return from our strategy; these periods correspond with the portions where the blue line is above orange, meaning that our strategy yields a higher return than the market index.

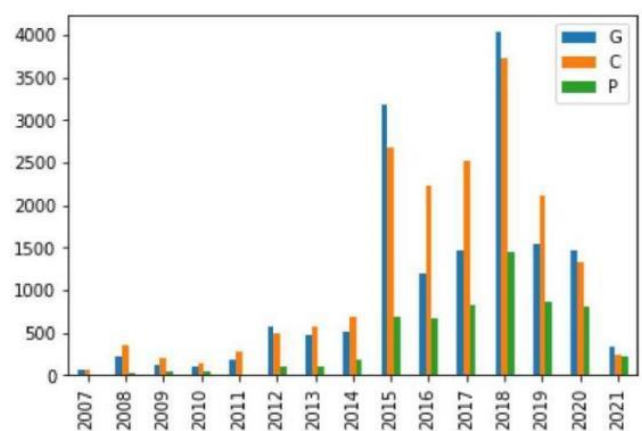

Figure 7: Number of announcements in year 2007-2021 classify by shareholder type

Note: $G$ represents manager; the blue bar is the number of released announcements of managers increasing their stake. $\mathrm{C}$ is company; the orange bar is the number of announcements associated with companies increasing stakes. $\mathrm{P}$ is individual in companies; the green bar is the number of announcements about individuals increasing stakes

According to Figure 6, except the year from July 2017 to July 2018 and from June to July in 2015, the strategy performs better than the overall market, producing positive abnormal return. This is a solid demonstration of the effectiveness of our strategy. The return from the strategy follows a steady growing trend 
until July 2015, where the rate of return the strategy yields experiences a steep rise. July 8th of the same year, CSRC published a notification. The notification encourages shareholders to wisely utilize increasing stakes as an incentive approach to stabilize stock market, when experiencing consecutive drop in stock price [4]. In Figure 7, a surge of number of announcements released in 2015 is clearly presented, which corresponds with the effect of governmental encouragement. The surge in announcement number also offers an explanation to the sudden increase in our strategy return. Hence, we deduce a relationship between the performance of the strategy and the number of the announcements: our strategy have a better performance with higher number of announcements released.

\section{CONCLUSION}

Chinese government has recognized the impact of shareholders increasing their stakes on the financial market, and hence, starts to encourage the behavior and meanwhile, strengthen the openness and transparency of the event in recent years. Arguments related to shareholders' changes in stakes is not a novel topic. In the academic field, many researchers and scholars hold controversial viewpoints on the behavior of shareholders increasing stake, and the results of many research are still not universally applicable due to the difference of stock market structure and policy orientation.

However, in this study, we focuse on the public announcements of shareholders increasing stakes and prove the existence of a positive impact from these announcements to the stock price. Through the comparison among different shareholder types, we discover that the announcements associated with managers increasing their stakes produce in the highest possibility of an increase in stock return than the other two. We also justify the feasibility of designing a profitable investment strategy based on the events by illustrating a notable excess return from the strategy in comparison with the market return. Overall, we add some insights to this long-standing topic and prove our hypothesis to be correct.

\section{REFERENCES}

[1] Securities Times China. Major Shareholders Increase Stakes, A Growth in Confidence or A Bait?, 2019.

[2] China Securities Regulatory Commission (CSRC). Regulations Regarding to Shareholding and Changing by Directors, Supervisors, and Senior Managers of Listed Companies, 2007.

[3] Bin Wang Longbing $\mathrm{Xu}$. Shareholders' Stake Increase under Equity Pledge: A 'Value Signal' or 'Behavior Signal'?, 2021.
[4] The Central Government of People's Republic of China. Notification from the CSRC to Encourage Major Shareholders and Executives of Listed Companies to Increase Their Stock Holdings, 2015.

[5] Hui Wang Xingjuan Huang, Zichun Yan. Investor Relations Management, Major Shareholder Increase and Corporate Performance, 2014. 